\title{
OPTIMIZATION OF TRANSIENT PRODUCTION CONTROL
}

\author{
Zsolt Harangozo - University of Miskolc, Faculty of Economics
}

dx.doi.org/10.18374/EJM-13-2.14

\begin{abstract}
Lean literature unanimously advocates transition of push production control to pull where possible, but very little is written about the mechanics of transition process or the behavior of systems in Lean transition. The fundamental element of this transition is conversion of a single processing stage from push to pull. At the same time, they are moving the interface for customer orders from the beginning of the production line towards the end of the production line. This change reduces the average time that customers wait for fulfillment of their orders. During this transition, the stage experiences a surge in its workload.
\end{abstract}

Keywords: production control; simulation modeling; transient behavior; optimization 